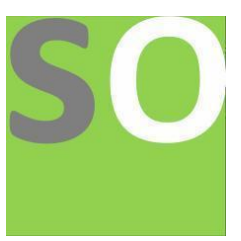

Article title: A New Stock Trade Technical Indicator

Authors: Kate Qian[1]

Affiliations: California Connections Academy[1]

Orcid ids: $0000-0002-4844-567 X[1]$

Contact e-mail: kqa2464@gmail.com

License information: This work has been published open access under Creative Commons Attribution License http://creativecommons.org/licenses/by/4.0/, which permits unrestricted use, distribution, and reproduction in any medium, provided the original work is properly cited. Conditions, terms of use and publishing policy can be found at https://www.scienceopen.com/.

Preprint statement: This article is a preprint and has not been peer-reviewed, under consideration and submitted to ScienceOpen Preprints for open peer review.

DOI: 10.14293/S2199-1006.1.SOR-.PPYQHIT.v1

Preprint first posted online: 17 September 2021 


\title{
A NEW STOCK TRADE TECHNICAL INDICATOR
}

\author{
Kate Qian \\ California Connections Academy
}

\begin{abstract}
This paper is focused on the new stock trade technical indicator that I developed to help indicate whether the stock is in an uptrend or downtrend. The new technical indicator is compared with the moving average convergence divergence (MACD) crossover and histogram to determine the accuracy of each technical indicator. The comparison shows that the new technical indicator had a higher accuracy percentage, as well as fewer losses, compared to the MACD crossover and histogram.
\end{abstract}

\section{Introduction}

Stock market prediction has always been a fascinating research topic, as well as a significant challenge due to its complexity and risks. The most difficult job in the stock market is analyzing historical data and making decisions that improve investment returns while minimizing losses. To make this job easier, there are technical indicators that can help indicate the stock trend. Although technical indicators will never be 100 percent accurate since they only analyze historical data to predict future price movements, they can certainly help.

This paper was first devised by looking at the losses on the moving average convergence divergence (MACD). I researched more than 20 stocks and their MACD and discovered that for some stocks, the MACD indicated a downtrend when the stock prices were uptrend, and vice versa.

For both the MACD and the new indicator, when the line intersects and is above the signal line, it indicates an uptrend in the stock or a buy signal. When the line intersects and is below the signal line, it indicates a stock downtrend or a sell signal. When the histogram is positive and above the zero line, the stock indicates that the stock is in an uptrend. When the histogram is negative and below the zero line, it indicates that the stock is in a downtrend. When the height decreases when above and below the zero line, it indicates that the stock trend's momentum is weakening.

My new technical indicator is more accurate than the MACD for most stocks which include: AAPL (Apple Inc), ZM (Zoom Video Communications), ADBE (Adobe Inc), PINS (Pinterest Inc), ETSY (Etsy Inc).

Acknowledgments: I would like to thank my mother, Kelly Qian, for her guidance and support 


\section{New Technical Indicator Formulas}

New Technical Indicator $=2 * \operatorname{EMA}(9)-$ EMA of EMA(9) - EMA(12)

$\operatorname{EMA}(\mathrm{N})=\mathrm{N}$-period Exponential Moving Average

N-period Double Exponential Moving Average (DEMA) $=2 * \operatorname{EMA}(\mathrm{N})$ EMA of EMA(N) [6] day)

$\mathrm{EMA}=($ Close - EMA (previous day) $) *$ Multiplier + EMA (previous

Multiplier $=(2 /($ time periods +1$))[5]$

Initial EMA = Simple Moving Average (SMA)

$\mathrm{SMA}=$ (number of days in a given period - the sum of stock closing prices in that period) / number of days in a given period [5]

The result of the above calculation is the 9-period DEMA line and the 12-period EMA as the signal line. The signal line can be plotted on top of the DEMA line. The new histogram measures the distance between the 9-period DEMA line and the 12-period EMA signal line. The new technical indicator outperforms the MACD.

The MACD histogram measures the distance between the MACD line and the MACD signal line. The MACD line can be calculated by subtracting the value of a 26 period Exponential Moving Average (EMA) from a 12 period EMA [3]. The MACD signal line equals the value of a 9 period EMA of the MACD line [4]. The time periods for the above EMAs are adjustable. The time periods I selected are the defaults [3]

\section{Comparison of Some Stocks with MACD and the New Technical Indicator}

The time period for all of the following chart data is from $08 / 6 / 20$ to $08 / 6 / 21$

\subsection{AAPL}

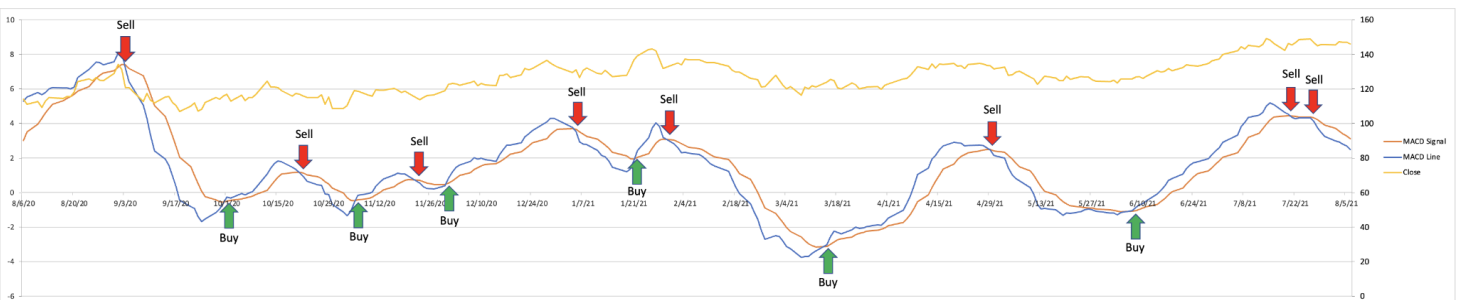

Fig. 1. MACD for AAPL (with arrows) [7] 


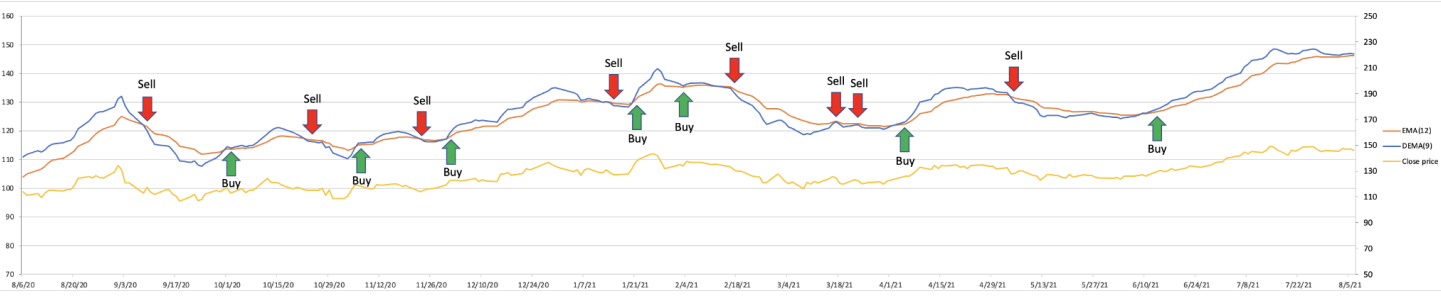

Fig. 2. New Indicator for AAPL (with arrows) [7]

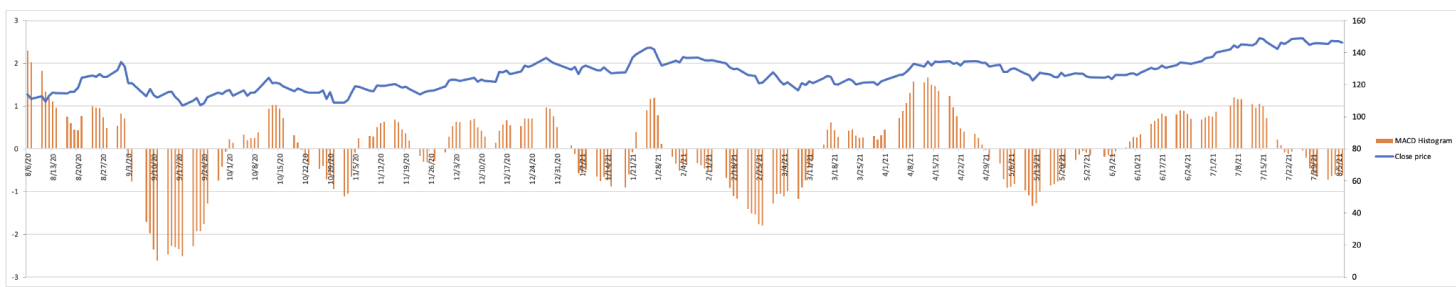

Fig. 3. MACD Histogram for AAPL [7]

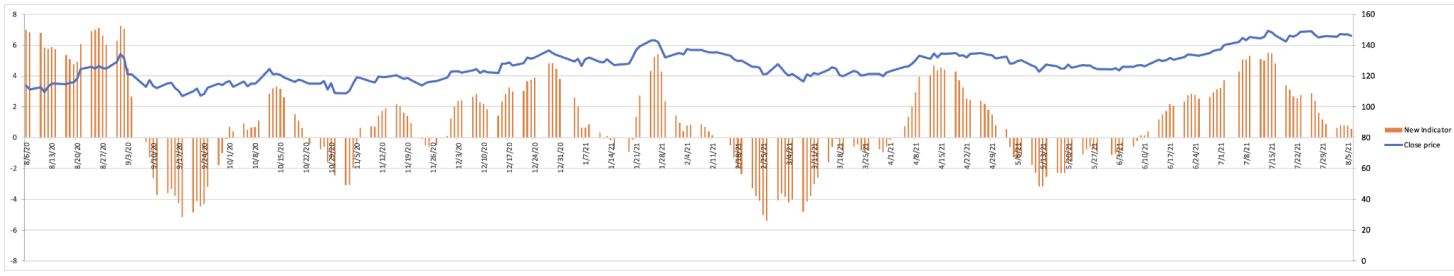

Fig. 4. New Indicator Histogram for AAPL [7]

For Figure 1, the MACD generates 6 buy signals and 7 sell signals with 3 losses. For Figure 2, the New Indicator generates 7 buy signals and 8 sell signals with 1 loss. For example, on Figure 3, from 7/21/21 - 8/6/21, the histogram indicates a downtrend while the stock close price had an uptrend. For Figure 4, from $7 / 21 / 21-8 / 6 / 21$, the histogram indicates an uptrend while the stock close price had an uptrend. The MACD had an accuracy of $76.92 \%$ while the New Indicator had an accuracy of $93.33 \%$.

\section{$3.2 \mathrm{ZM}$}

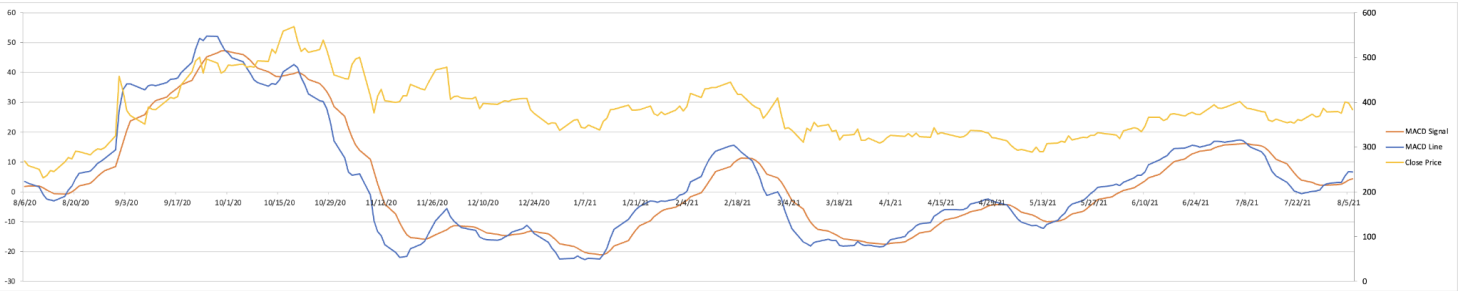

Fig. 5. MACD for ZM [8] 


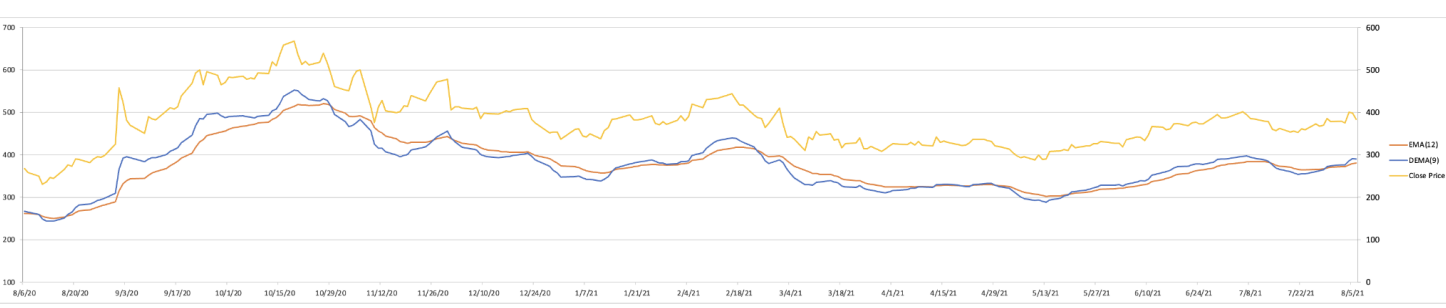

Fig. 6. New Indicator for ZM [8]

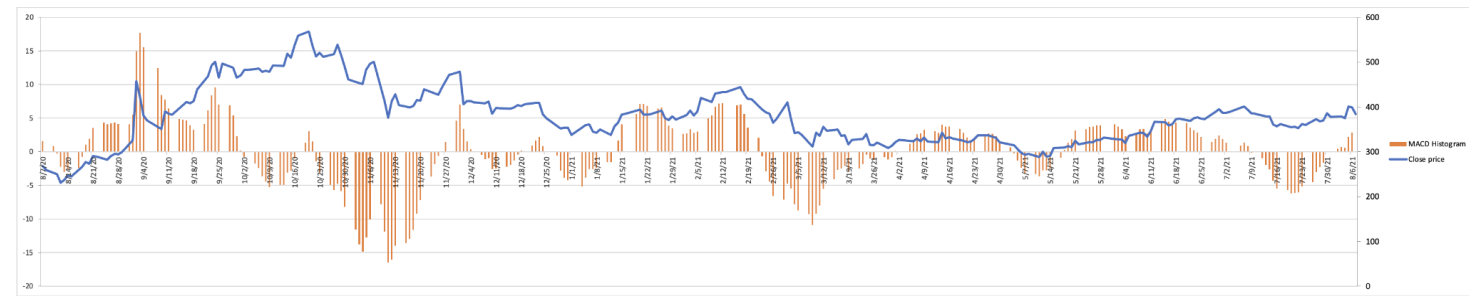

Fig. 7. MACD Histogram for ZM [8]

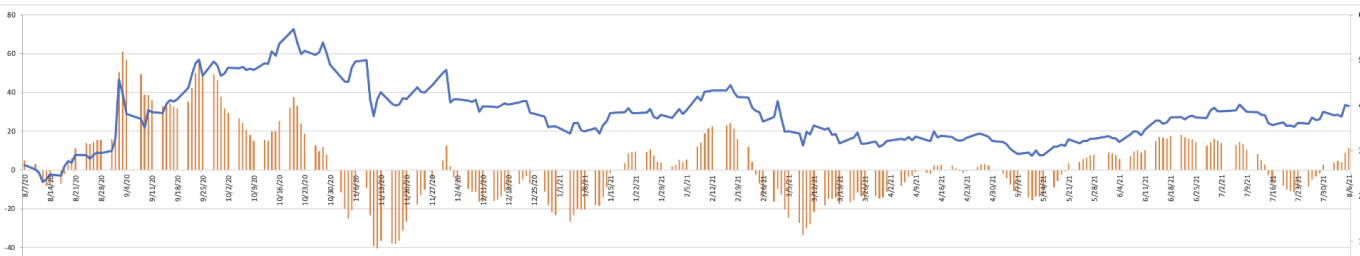

Fig. 8. New Indicator Histogram for ZM [8]

For Figure 5, the MACD generates 8 buy signals and 9 sell signals with 2 losses. For Figure 6 , the New Indicator generates 6 buy signals and 7 sell signals with 1 loss. For example, on Figure 7, from 10/5/20 - 10/16/20, the histogram indicates a downtrend while the stock close price had an uptrend. For Figure 8 , from $10 / 5 / 20$ - 10/16/20, the histogram indicates an uptrend while the stock close price had an uptrend. The MACD had an accuracy of $88.24 \%$ while the New Indicator had an accuracy of $92.30 \%$.

\subsection{ADBE}

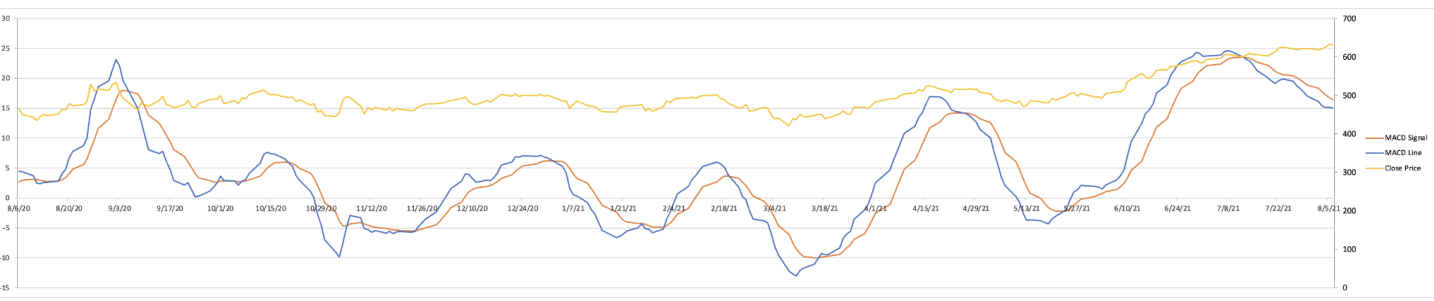

Fig. 9. MACD for ADBE [9] 
Fig. 10. New Indicator for ADBE [9]

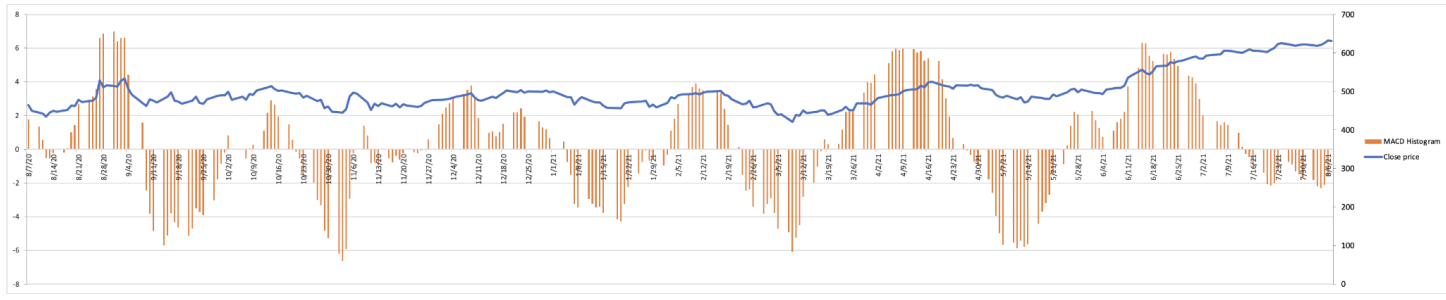

Fig. 11. MACD Histogram for ADBE [9]

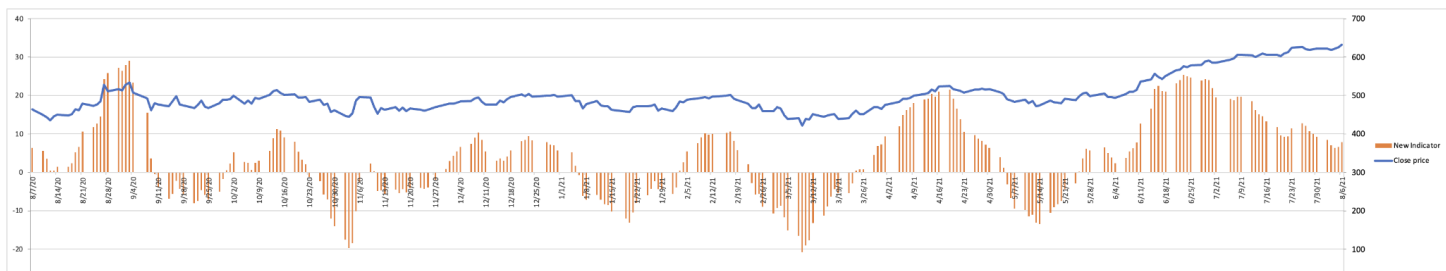

Fig. 12. New Indicator Histogram for ADBE [9]

For Figure 9, the MACD generates 8 buy signals and 10 sell signals with 2 losses. For Figure 10, the New Indicator generates 8 buy signals and 6 sell signals with 0 losses. For example, on Figure 11, from 7/14/21 - 8/6/21, the histogram indicates a downtrend while the stock close price had an uptrend. For Figure 12 , from $7 / 14 / 21-8 / 6 / 21$, the histogram indicates an uptrend while the stock close price had an uptrend. The MACD had an accuracy of $88.89 \%$ while the New Indicator had an accuracy of $100 \%$.

\subsection{PINS}

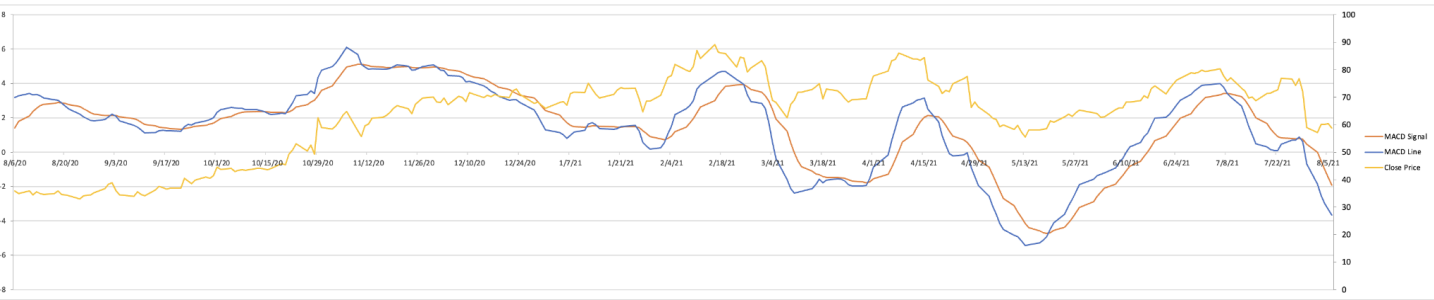

Fig. 13. MACD for PINS [10] 
Fig. 14. New Indicator for PINS [10]

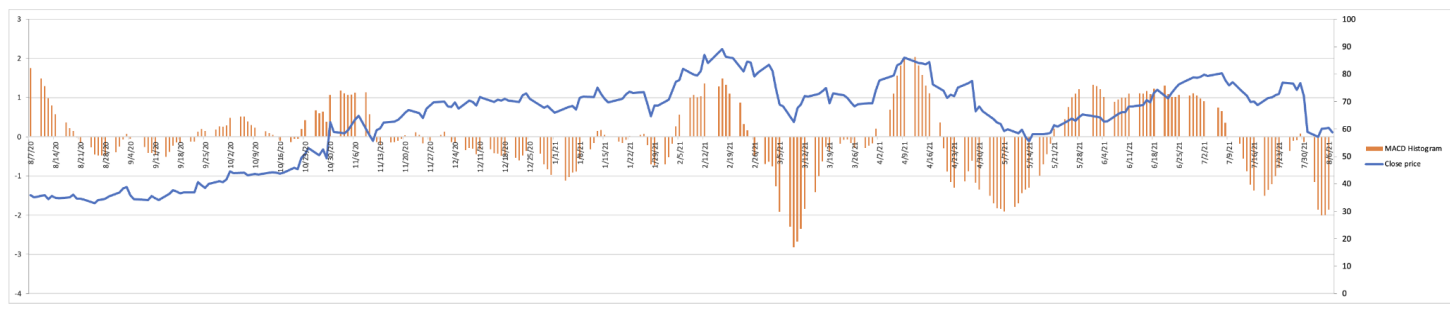

Fig. 15. MACD Histogram for PINS [10]

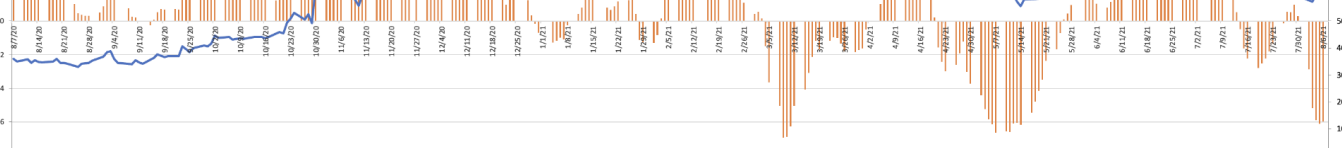

Fig. 16. New Indicator Histogram for PINS [10]

For Figure 13, the MACD generates 8 buy signals and 13 sell signals with 5 losses. For Figure 14, the New Indicator generates 8 buy signals and 6 sell signals with 1 loss. For example, on Figure 15, from 11/11/20 - 12/23/20, the histogram indicates a downtrend while the stock close price had an uptrend. For Figure 16, from 11/11/20 - 12/23/20, the histogram indicates an uptrend while the stock close price had an uptrend. The MACD had an accuracy of $76.19 \%$ while the New Indicator had an accuracy of $92.86 \%$.

\subsection{ETSY}

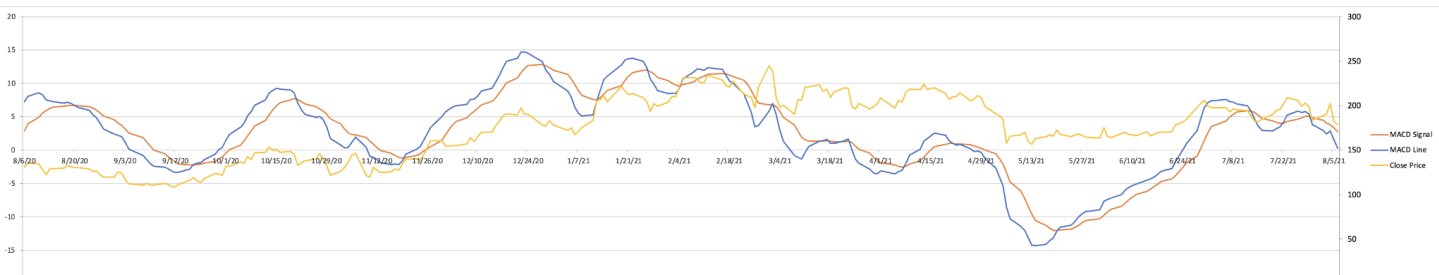

Fig. 17. MACD for ETSY [11] 


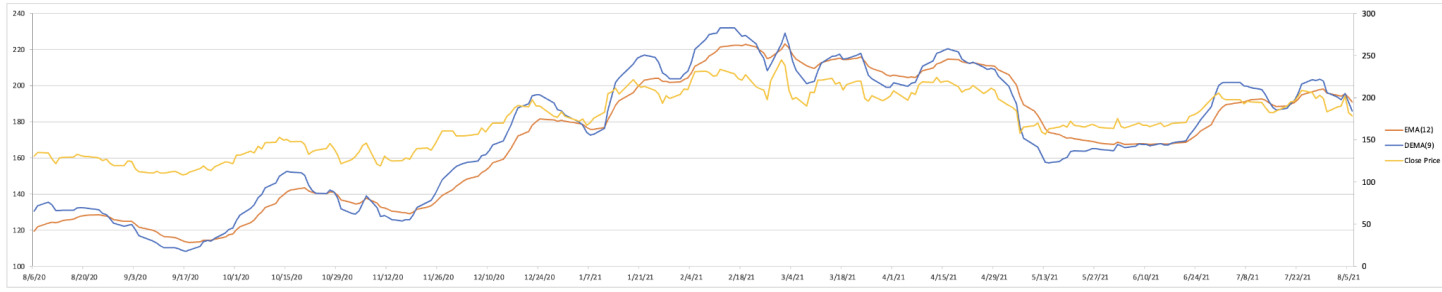

Fig. 18. New Indicator for ETSY [11]

Fig. 19. MACD Histogram for ETSY [11]

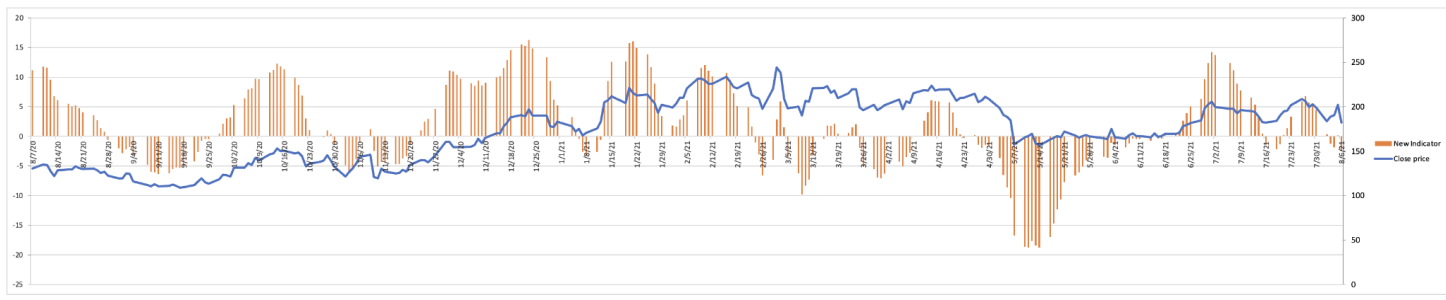

Fig. 20. New Indicator Histogram for ETSY [11]

For Figure 17, the MACD generates 8 buy signals and 11 sell signals with four losses. For Figure 18, the New Indicator generates 11 buy signals and 11 sell signals with three losses. For example, on Figure 19, from 1/28/21 - 2/5/21, the histogram indicates a downtrend while the stock close price had an uptrend. For Figure 20, from 1/28/21 - 2/5/21, the histogram indicates an uptrend while the stock close price had an uptrend. The MACD had an accuracy of $78.95 \%$ while the New Indicator had an accuracy of $86.36 \%$. 


\section{Conclusion}

In this paper, the new technical indicator I devised is compared with the moving average convergence divergence (MACD) crossover and histogram to determine the accuracy of each technical indicator. I found that the new technical indicator had a higher accuracy percentage, as well as fewer losses, compared to the MACD crossover and histogram.

Currently, the new indicator misses some buy or sell signals and requires greater accuracy to avoid losses. However, no single indicator will always produce accurate results. Therefore, additional research efforts will be directed toward refining the accuracy of a combination of indicators, including my own. Furthermore, the new technical indicator's general applicability must be examined further by applying it to a broader range of stocks. 


\section{Reference}

1. Pradipbhai, N. P. (2012). Comparison Between Exponential Moving Average Based MACD with Simple Moving Average Based MACD of Technical Analysis. International Journal of Scientific Research, 2(12), 189-197. doi:10.15373/22778179/dec2013/60

2. Moving Average Convergence/Divergence (MACD). (2015). 12 Simple Technical Indicators, 43-50.

doi:10.1002/9781119204428.ch4

3. What is macd? - moving average convergence/divergence. Fidelity. (n.d.).

https://www.fidelity.com/learning-center/trading-investing/technicalanalysis/technical-indicator-guide/macd.

4. Fernando, J. (2021, August 21). Moving average convergence divergence (macd) definition.

Investopedia.https://www.investopedia.com/terms $/ \mathrm{m} / \mathrm{macd}$.asp.

5. Maverick, J. B. (2021, June 5). How is the exponential moving average (EMA) formula calculated? Investopedia.

https://www.investopedia.com/ask/answers/122314/what-exponentia 1-moving-average-ema-formula-and-how-ema-calculated.asp.

6. Mitchell, C. (2021, June 15). Double exponential moving average (DEMA) definition and calculation. Investopedia.

https://www.investopedia.com/terms/d/double-exponential-moving-av erage.asp.

7. Yahoo! (2021, August 21). Apple Inc. (AAPL) stock historical prices $\&$ data. Yahoo! Finance.

https://finance.yahoo.com/quote/AAPL/history?p=AAPL.

8. Yahoo! (2021, August 21). Zoom Video Communications, Inc. (ZM) Stock Historical Prices \& Data. Yahoo! Finance.

https://finance.yahoo.com/quote/ZM/history?p=ZM.

9. Yahoo! (2021, August 21). Adobe Inc. (ADBE) stock historical prices $\&$ data. Yahoo! Finance.

https://finance.yahoo.com/quote/ADBE/history?p=ADBE.

10. Yahoo! (2021, August 21). Pinterest, Inc. (PINS) stock historical prices \& data. Yahoo! Finance.

https://finance.yahoo.com/quote/PINS/history?p=PINS.

11. Yahoo! (2021, August 21). Etsy, Inc. (etsy) stock historical prices \& data. Yahoo! Finance.

https://finance.yahoo.com/quote/ETSY/history?p=ETSY. 